\title{
HACIA UNA INTERPRETACION DE LA DICOTOMIA DE MUNDOS NARRATIVOS EN LA PASION TURCA DE ANTONIO GALA.
}

\author{
Dr Abdelaal Saleh Taha \\ Asistente profesor - Faculty of Alsun - Minia Univrsity
}

\section{La pasión turca}

${ }^{1}$ de Antonio Gala tuvo una buena acogida por parte de los lectores. En una sola década, 1993-2003, se publicó catorce veces. A nivel de crítica la obra ha sido de poca fortuna. Al contrario de otras obras famosas del propio escritor y otros, las ediciones de La pasión turca no disponen de prólogos, ni estudios. La única edición que tiene prólogo, por cierto muy pequeño y de carácter general, es la de Carmen Rigalt. Por su parte, Astrid A. Billat ha llamado la atención sobre la escasez de material científico y estudios sobre esta novela (2004: 43).

Por otra parte, Emilia Cortes Ibáñez señala que La pasión turca "es un canto al amor en el alma de una mujer" (2017: 35 y 39). En ella, el novelista andaluz narra la experiencia vital de Desideria Oliván o Desi. en busca de su felicidad. Dado su matrimonio fracasado debido a la impotencia sexual de su marido, y la vida monótona y rutinaria en Huesca, ella encuentra dicha felicidad en una relación amorosa con un joven turco, Yamam. Su dilema es que su amor no ha sido correspondido en la misma forma e intensidad por parte de su amante. Para Yamam su relación con ella es una más de sus muchos amores pasionales que estaba acostumbrado a tener.

Esta experiencia vital de la protagonista comprende casi toda su vida: su infancia, su juventud, su vida conyugal y su vida amorosa. Este tránsito a lo largo del tiempo se traduce en cambio continuo del espacio. De este modo, Desideria se traslada de un sitio a otro, visita a Colombia, Egipto, Siria, Turquía y Francia. Termina su vida residiendo en Estambul, que le da la oportunidad de viajar mucho en Turquía y ofrecer una descripción detallada a la misma. El resultado de estos viajes y su residencia final en esta famosa ciudad turca es una creación novelística compuesta por dos mundos narrativos. Ya estamos ante la eterna binaria: el Oriente, representado por viajes hacia Egipto, Siria y Turquía, y el Occidente presentado por Colombia, España y Francia. Desde el primer momento de lectura de la novela se observa una cierta diferencia en los recursos narrativos utilizados por el novelista al referirse a un mundo u otro, tomando perspectivas distintas y realizando una selección consciente de los elementos narrados, que es oportuno exponer, analizar e interpretar. 


\section{Dr Abdelaal Saleh Taha}

Por todo ello, creemos que una investigación sobre este aspecto, es decir nuestro tema: Hacia una interpretación de la dicotomía de mundos narrativos en $L a$ pasión turca, tiene su justificación, expone dichos mundos con sus peculiaridades y sus perspectivas correspondientes, y aspira a ofrecer una interpretación que sea lógica y aceptable al respecto. Como consecuencia de ello, el trabajo se divide en dos partes, precedidas por una introducción que plantea unas bases teóricas imprescindibles para su desarrollo posterior. La primera es un análisis de la dicotomía en la novela resaltando la focalización que se toma la forma de aplicar dos perspectivas; a través de los distintos elementos narrativos que se consideren oportunos, tales como la estructura, los personajes, y realidades sociales. La segunda, hacia una interpretación, se trata de una explicación de los posibles motivos que promovieron al novelista a realizar esta dicotomía presentando el Oriente cómo se verá al final con una introducción donde se ofrece una evaluación general, que sintetiza el resultado del análisis de la obra y establece algunos criterios necesarios para una justa explicación.

\section{Bases teóricas}

Habida cuenta de que en La pasión turca podrían existir dos mundos narrativos. Normalmente, estos serían resultado directo del uso del punto de vista, la focalización o la perspectiva. En este apartado nos interesa hacer recordar algunos puntos que son de suma importancia para el desarrollo del presente trabajo sobre esta técnica y cómo figura en La pasión turca.

En primer lugar, la focalización es "la elección -según Darío Villanueva- de una o más perspectivas desde las que abordar el conjunto de la historia que se quiere transformar en un discurso modelizado" (1995: 191). Gil Casado considera que la focalización coincide con la perspectiva y lo define como "la posición que toma el escritor para captar el sentido y la esencia de la realidad". Apoya su explicación por la opinión de Juan Goytisolo quien indica que "narrar es tomar una posición sobre lo se narra" (1975: 63-64). Por su parte, Antonio Garrido Domínguez señala que el punto de vista funciona como categoría ideológico-compositiva y condiciona de forma directa la organización del relato en sus diferentes estratos. (1993: 128). Casado advierte que "una perspectiva errónea falsea la novela, una falta de perspectiva priva la novela de su verdadero sentido" (1975: 63-64). Se puede deducir dos puntos: la extrema necesidad de la perspectiva, y la importancia de que se tome de forma correcta. En caso contrario la obra narrativa pierde su sentido o se falsea la realidad que se narra.

En relación con la forma de la perspectiva en La pasión turca, diríamos que se presenta primero en el uso del YO, que confiere la máxima credibilidad ante los 
ojos del lector (Garrido Domínguez, 1993:112). Segundo, en el manejo de lo que llama Darío Villanueva "una omnisciencia multi-selectiva" que él la iguala a un gran escenario donde los focos de luz se dirigen a diferentes enclaves del espacio escénico (1995: 26). Este recurso narratológico toma en esta obra la forma de un proceso de selección constante, eligiendo elementos negativos en uno frente a otros positivos en el otro que conduce a una falta de correspondencia o paralelismo entre personajes, objetos, espacios, etc., contenidos en los dos mundos. Una advertencia importante que se debe destacar, se refiere al espacio que ocupa cada mundo, y sus consecuencias a la hora de hacer el análisis. El primer mundo, el occidental, consta de unas veinte páginas, mientras que el segundo, el oriental, abarca unas ciento y diez páginas. Como consecuencia de esta distribución desigual, a la hora de realizar la búsqueda de un universo a otro nuestro interés tendrá la misma distribución, concediendo mayor espacio para el oriental mientras que el occidental va a funcionar como introducción o contraste. Esto se debe a que este mundo primero le falta muchísimos detalles que existen en el segundo. Dado lo anterior, el método seguido es ofrecer el segundo mundo con notas del primero que ayudan a desarrollar la hipótesis de este trabajo: la dicotomía de mundos narrativos y sus posibles interpretaciones.

\section{La dicotomía en La Pasión Turca}

Ahora vamos a observar la dualidad en la estructura, los personajes, la realidad social y el nivel léxico- semántico.

\subsection{La dicotomía en la estructura}

La estructura es el primer aspecto donde se manifiesta la dicotomía. La pasión turca se compone de cuatro capítulos grandes que reciben el nombre de cuaderno, y están escritos en primera persona, "YO". Estos capítulos están precedidos por una "advertencia" y seguidos por un "epílogo", que están plasmados en tercera persona por un narrador omnisciente, donde se notifica el papel del autor en la obra, y da noticia sobre el desenlace trágico de la protagonista.

El primer mundo narrativo, el occidental, se ofrece en el capítulo primero que cuenta la infancia y juventud de la protagonista y su contorno social (5-26). El segundo mundo, el oriental, se relata en el resto de la obra, unas once páginas del primero (27-38), y los tres capítulos siguientes. En esta parte, Gala narra los sucesos de dos viajes a Egipto y Siria respectivamente. Además, se nos ofrece el comienzo, desarrollo y fin de las relaciones amorosas entre la española Desideria y el turco 


\section{Dr Abdelaal Saleh Taha}

Yamam. En su desarrollo de su presentación de un mundo a otra, se observa que el autor de vez en cuando va a saltar de un mundo a otro. Primero, utiliza la prolepsis para adelantar cosas del segundo mundo y la analepsis, recordando cosas que pertenecen al primer mundo, y subrayan dicho contraste. Estas últimas son evocación de recuerdos felices ocurridos en el primer mundo, el occidental, que chocan de forma particular con los momentos tristes que la protagonista vive en el segundo universo, el oriental. Igualmente, en su narración del mundo oriental, el autor hace un salto hacia el mundo occidental en forma de viajes relámpagos a España y Francia que confirman la diferencia existente entre estos dos mundos expuestos a lo largo de la obra. Así, a nivel estructural, la obra refleja una dicotomía que se da en la descripción de dos mundos narrativos con diferentes formas de novelizar: el primero, el occidental, se compone de tres lugares Colombia, España y Francia, y el segundo, el oriental, incluye, también, tres países, Egipto, Siria y Turquía, los dos más importantes del mundo árabe y el más prestigioso a nivel islámico.

\subsection{La dicotomía en los personajes}

Es muy difícil dar una cifra exacta del número de los personajes en La pasión turca. De forma general, el número total, según nuestro recuento, sobrepasa los sesenta. En este sentido, nos encontramos con la primera paradoja, a pesar del espacio exiguo que ocupa el mundo occidental, casi el cuarto de la obra, cuenta con más de treinta personajes, mientras que el oriental consta de menos de veinticinco personajes. Otra prueba que confirma el carácter particular de la forma de novelar de cada mundo es la naturaleza de personajes de cada mundo. Los occidentales, generalmente, tienen nombres y apellidos, pertenecen a la elite de su sociedad, entre médicos, abogados, cónsules, etc. y han merecido una caracterización casi detallada por parte del autor. Entre los más destacados encontramos: Ramiro es un directivo de empresa de seguros, Pablo acosta, un agente en el Interpol, y Denis es un director de una firma francesa. Los del mundo oriental los comentamos en su apartado correspondiente.

\section{- Personajes Orientales}

Como hemos adelantado, aunque el mundo narrativo oriental representa el $75 \%$ de la totalidad de obra, el número de sus personajes es menos que los occidentales. Además, casi todos no tienen nombres, ni profesiones conocidas, respetables o modestas. Son muy pocos los que tienen nombre, como Yamam, Harife, una criada, etc. Esto se va a reflejar en el análisis de los personajes que se concentra sobre Yamam ya que es el único personaje que tiene una permanente capacidad de sorpresa, lo que nos permite clasificarle de "redondo", o complejo. Esta capacidad según Garrido Domingo- es esencial para esta clasificación y "una de las cualidades 
distintivas de la novela" (1993: 93). También, es el único personaje oriental que mereció la atención de los críticos. La mayoría de sus conciudadanos son meras referencias con su glosa peyorativa como: sombríos, hambrientos vociferantes y bebidos, oscuro con una cicatriz, etc. y siempre actúan de lejos. Esta caracterización tan especial es producto de los modelos narrativos que el autor decidió incorporar a su obra, sobre todo el policíaco, que exige tipos raros, sospechosos y con aspectos espantosos, ya que se mueven dentro del mundo del crimen.

El primer personaje oriental es Yamam. No cabe duda de su importancia como protagonista principal de la obra. Antonio Gala subraya su importancia, llamándolo "el único", concediéndole la calidad de representante del pueblo turco: (Yamam) "fue él Mismo \{sic.\} quien me enseñó lo que es el pueblo turco" (p 72). Su nombre aparece al principio de la misma, en la página 11, con noticias breves de las cuales se sabe que es lo más importante para Desideria; la protagonista. Astrid A. Billat llama la atención sobre el uso continuo por parte del novelista de la prolepsis en su introducción de Yamam como forma de mantener la curiosidad del lector hacia él (2004: 41). De ahí viene la importancia de profundizar en el análisis de su caracterización con el fin de reconstruir la imagen que le hizo su autor de él y por lo siguiente del pueblo turco. Su caracterización se realiza a través de cuatro aspectos: el punto de vista del narrador, su discurso e ideas, su exagerada capacidad sexual, y considerar esta cualidad como una parte de un rasgo común, la sensualidad, de todo el pueblo turco.

El primer aspecto en la caracterización de Yamam es el punto de vista del narrador hacia él. Desde el principio, Antonio Gala lo crea como personaje misterioso, cuya vida está envuelta en relaciones sospechosas. Estas se evolucionan de forma progresiva hasta desvelar su entidad auténtica como miembro de la mafia turca. (pp. 39, 58, 60 y117).En el primer viaje de negocios de Desi a Estambul, la policía del aeropuerto de Madrid la interrogó sobre su negocio en general, y la entidad de Yamam en particular (pp. 50, 117 y 125). Acercándose hacia el final, las sospechas se aclararon. Yamam encargó a Desideria de visitar a su jefe mafioso. El escritor, como en los finales de las obras de intriga policíaca o romántica (véase 3.), resuelve el carácter de su personaje antedicho.

El segundo aspecto en la caracterización general de Yamam es su carácter como payaso a través de su soberbia e ideas ultranacionalistas incongruentes que se reflejan en su discurso, a nivel de acción y contenido. En cuanto a su acción, Gala subraya esta cualidad al describirle de la forma siguiente: "Echaba chispas por sus enormes ojos, irritado, paseaba como un león enjaulado, etc.”(p 72). Respecto al 
contenido, sencillamente, no reconoce las aportaciones de otros pueblos en la civilización en la humana. Para él, su país es el mejor en el pasado y el presente. Ataca a los europeos, sus interlocutores, haciéndolos conocer que "los turcos vivían en un mundo de placeres y voluptuosidades cuando ellos aún estaban en la oscuridad de la Edad Media" (pp. 41 y 72). La parte más negativa de su discurso corresponde a la aportación cívica de los musulmanes. "Lo negativo de Turquía de hoy -según élarranca de los árabes y de los persas; de lo musulmán, en una palabra". (p 72). Como contraposición a esta parte ya viene su juicio favorable respecto a su cultura, a su pueblo, a su patria y a la personalidad turca. Él confirma el papel de su patria en la civilización humana al decir: "allí nació la civilización occidental".

El tercer aspecto de la caracterización de este personaje es su capacidad sexual, que se podría pensar como algo positivo. Esta cualidad según la tradición occidental es un agravio con el cual se descalifica al enemigo. Jerez Farrán señala que esto podría tener relación con algunas ideas del Cristianismo que favorecen al celibato. (1992: 3-18). Por eso, esta cualidad como ofensa ha sido presente en todo momento que hubo necesidad de descalificar a los orientales, ya sea en la Edad Media (Juan Goytisolo, 1982: 75-76), o durante la Guerra Civil (Juan Goytisolo, (1982: 37 $38)$.

Esta faceta de su personalidad es la más importante a nivel de intriga y estructura de la obra. Desideria, en su realización como mujer: esposa, madre y amante, estaba motivada por esta cualidad. Su atracción por esta capacidad es lo que condujo a su residencia en Estambul, y la creación de la parte más importante del mundo narrativo oriental, que cupo, como mínimo, unas cien páginas. Sin esta cualidad hubiera sido difícil justificar dicha prolongación de este mundo que hubiera convertido en unas ligeras pinceladas, como las expuestas en los dos viajes a Egipto y Siria, sin la trascendencia que tiene en su forma actual, y la obra, a nivel estructural, hubiera debilitado. Para subrayar este rasgo, el autor utiliza todo tipo de recursos narrativos a su alcance como: la narración, con sus distintas formas, descripción física, contar algunas escenas eróticas y la emisión de juicios y comentarios por parte de su amada. Debido a que la obra está repleta de este tipo de descripciones, y el autor, en muchos casos, las añade para engordar su obra, como lo habían comentado Emilia Cortes Ibáñez (2017: 39) y Manuel Asensio Moreno (1996: 124, 127, y 131) nosotros no vamos a reproducirlas sino solo señalamos su ubicación en la obra. Antonio Gala hace dos descripciones de Yamam: una externa (pp. 39, 40 y 41) y otra interna (p 52).Respecto a su forma de hacer el amor, la obra está llena de escenas eróticas que facilitan los datos necesarios. (pp. 43, 44 y 112). Otro aspecto que refleja su sexualidad lo constituyen los comentarios de la protagonista durante y después de los actos amorosos, como las siguientes: "Todo estaba bien: el mundo y mi vida" (pp. 
43 y 44). Compárese lo anterior con su comentario sobre otro acto erótico con su marido: "En ningún momento ni él ni yo perdíamos la cabeza" (p 15).También, se destaca el carácter singular de su sexualidad, estableciendo comparaciones entre él y los demás hombres que tuvieron una relación erótica con la protagonista, como su marido y sus amantes: Iván y Denis. Después de estas comparaciones la protagonista quedó convencida de que Yamam "era insustituible"(pp. 95, 111 y112). El último aspecto sobre su capacidad sexual es el número de relaciones eróticas que mantiene a lo largo de la novela y sus géneros. Sus detalles figuran en lo siguiente: él estaba casado con una paisana suya, mantuvo relaciones con Desideria, Blanche, y el secretario del escritor. Es conocido en la colonia española en Estambul por ser "mujeriego"(pp. 84 y 131).

El último recurso al recurre en su creación es utilizar a otros personajes a dar juicios sobre otros aspectos que es indiscutible su índole negativa para complementar la imagen deseada, como "holgazán", "Ése es capaz de vender a su madre", "una fama atroz: de mujeriego y de otras cosas" y "turco vulgar "(pp. 84, 139 y 115), "hombre bestial y violento" (A. Billat, 2004:36). Debido a lo anterior, Yamam y Desideria han sido los únicos personajes comentados por los críticos como Carmen Regalit (p 2) y Asensio Moreno (1996:136).

Después de este personaje principal vamos a referirnos a otros orientales. Como se señaló antes la mayoría de los personajes orientales en La pasión son meras referencias con su glosa peyorativa y siempre actúan de lejos. Cabe destacar que Gala expuso una galería de personajes de distintos índole: hombres, mujeres, urbanas, campesinas, chicos y mayores, etc. Para realizar esto, el novelista actúa de muchas formas. Reproduce la idea negativa que algunos extranjeros tienen sobre los turcos y ofrece algunos modelos de personas turcas que en muchos casos demuestran su carácter verídico. De los hombres, actúan de forma directa, Yamam, el jefe mafioso y el dueño de una cafetería. Éstos, excepto el último de ellos, son malísimos; un jefe mafioso y su subordinado Yamam. Mientras que aparecen de lejos y sin intervención directa su madre, su hermano y Mahmud, etc.

En cuanto a las mujeres turcas, su caracterización, en conjunto, es de índole desfavorable. En cuatro ocasiones Desideria confirma su rechazo de ser considerada o tratada como turca y piensa que ella es distinta, mejor. Este rechazo se debe a sus ideas respecto a las turcas que podrían ser una parte de una imagen de estereotipo. En ésta, la mujer turca tiene muy mal gusto en vestidos; acepta con resignación la autoridad del hombre. Es conformista, se queda en casa, engordándose, mientras que su marido está dando vueltas en el mundo. Además, su papel se limita a ser mujer; el 
hombre no la ve como compañera sino como un instrumento de su placer (pp. 73, 78 y 112). El autor ha ofrecido distintos tipos de mujeres turcas: unas urbanas y otras rurales. Éstas nunca actúan directamente sino de lejos, creando una imagen o un ambiente. Tampoco Gala olvidó la mujer trabajadora, representada en Harife, criada de la vieja Ariane en Estambul y en las campesinas en el campo quienes se caracterizan por su vestimenta tradicional, igual a su imagen en obras rurales españolas como la trilogía de García Lorca o la familia de Pascual Duarte de Cela, que refleja retraso y falta de modernidad.

De las urbanas se destacan: la viuda de un comerciante, la madre de Yamam y sus amigas. El escritor mostró su indecencia, su crueldad y sus malas costumbres. La viuda, advierte el autor, no lo hace falta ninguna celestina ya que ella sabe buscar a sus amantes. La madre de Yamam, partiendo de su actuación, en general y en los abortos de Desi, en particular, es símbolo de crueldad. El autor dibuja a sus amigas de una forma pintoresca y negativa:

Cinco o seis mujeres - todas vestidas de una manera falsamente europea- comían con fruición y hablaban con la boca llena, pasándose los platos de pastelillos, pastas y emparedados ( $\mathrm{p} 103)$.

Nos queda en este punto resaltar la opinión del autor sobre la falta de igualdad entre hombres y mujeres a nivel de tratamiento. Para el primer punto, el autor cuenta una costumbre turca, según la cual, las familias, al nacer el varón, plantan unos terrenos con árboles que se cortan al tiempo de su boda para financiarla. No hacen lo mismo para las hembras, ya que -según Yamam- "estas no cuentan". De forma igual, en los pueblos y ciudades pequeñas no se permite la entrada de mujeres en los lugares públicos, como restaurantes y cafeterías porque "estropean el ambiente", además, para "mantener el local limpio sin colillas e impedir que se quemen manteles o asientos". Igualmente, los hombres pasan su tiempo en la cafetería para escapar de que sus mujeres les dieran la lata (pp. 58 y 59 ).

Para completar su presentación global respecto a los turcos, Antonio Gala utiliza a muchos personajes. En esta fase, parte de lo particular a lo general, convirtiendo un rasgo concreto de Yamam, su sensualidad, en una caracterización común de todo el pueblo turco. Yamam reconoce la sensualidad de sus conciudadanos y prohíbe a Desideria a poner pantalones, ya que "ciñan su trasero", razonándolo por "Yo conozco a mi gente" ( $p$ 78) y le advierte que el turco, en general "es macho como nadie" (p 60). Este personaje turco llama la atención del arraigo histórico de esta cualidad, la sensualidad, al decir: "Cuando ustedes aún estaban en la oscuridad de la Edad Media, nosotros vivíamos en un mundo de placeres y voluptuosidades"( $p 41)$. 
Gala nos ofrece muchas escenas que demuestran esta cualidad. Entre otras, el jefe mafioso, cuya edad pasaba los setenta años, ordena a Desi a desnudarse y realiza una masturbación; como si fuera adolescente, contemplando su cuerpo (p 132). Yamam organiza otra erótica entre Desideria, Blanche y él.

En su perspectiva de uso de personajes que acentúan otros aspectos despectivos del pueblo turco como: el engaño, el robo, etc. se destaca la vieja Ariane. Ésta vieja estaba dispuesta a vender sus alfombras a una persona que "no sea turca"; y para ella: [Todos los turcos] "sólo saben pedir dinero; y siempre engañan, siempre roban" (pp. 89 y 91). Desi comenta que los extranjeros en Estambul no tienen confianza en los turcos y siempre piensan que cualquiera turco desea sacar tajada de ellos. Ella, por su parte, les da la razón y no puede reprochárselo. Además, el autor apoya este juicio con una escena narrativa cuando un niño, de un tirón, arrancó del cuello de Desi una cadena de oro (p 119). Esta cualidad, la de engaño y robo, individual se convierte en una base de los negocios. Yamam comenta que los comerciantes turcos presumen de ser los más honrados del mundo y la verdad es que:

Son famosos por su habilidad para engañar, y su timbre de gloria y de propaganda es que engañan menos que los vecinos o, mejor aún, que engañan más sin que se note ( $\mathrm{p} 60$ ).

Además, le extraña que los sirios no hayan engañado a Pablo Acosta. Éste le contesta que los comerciantes turcos son "los más ladrones" ( $p$ 123).El protagonista turco describe el mundo comercial en su país en estos términos:

Una jauría, una selva donde no hay aliados, ni escogidos; a nadie se reconoce primacía. Se trata de vender, lo que sea, aunque sin dar ocasión a que la ley intervenga (p 71).

Luego subraya la relación de la actividad comercial con la mafia: “ Aquí se vienen a buscar las divisas extranjeras para los negocios imposibles de hacer al descubierto con dinero cambiado en bancos oficiales" ( $\mathrm{p} 71$ ).

\section{- Personajes occidentales}

Recuérdese del comentario hecho al principio de este apartado respecto a los personajes occidentales, ya es el momento de demostrar. El primero personaje es Desideria, la protagonista de la novela, quien goza de muchas cualidades positivas, inexistentes en Yamam. Es romántica, abnegada y legal. Su gran cualidad es su amor 


\section{Dr Abdelaal Saleh Taha}

hacia los demás sobre todo su padre. El autor aprovecha el accidente de tráfico que tuvo su marido para darla juicios muy positivos. Sus amigas dicen: "Desi se está portando con una abnegación insuperable". Por su parte, el padre Alonso le dijo: "Eres una santa. [...] Te pongo de ejemplo a mis penitentes" (pp. 17, 35 y 39). Rechaza hacer el aborto de su segundo embarazo ya que su religión no lo permite (p 82). Cuida a los hijos de Yamam, enseña a Mahmud a hablar el español, visita con frecuencia a Ariane, y compra comida para los pájaros y da limosnas a los pobres ( $\mathrm{p}$ 115). Se entristece al ver a un hombre que pega a un oso ( $p$ 108).

El segundo personaje es Ramiro, marido de Desi., conocido por muchas cualidades físicas, psíquicas y personales positivas. Es guapo, ambicioso, tolerante, generoso, cariñoso y tiene una fuerte personalidad (pp. 5, 8,14, 16 y 48). La gran cualidad de Ramiro es su religiosidad. Se podría decir que ésta marca todo tipo de actividad o relaciones en su vida, llegando a veces a la exageración. Conoció a su mujer en una iglesia o pasó su noche de boda en un monasterio. El hecho religioso le preocupa casi siempre, sea en su viaje a El Cairo o en su vida cotidiana, donde cumplía con sus deberes diarios al pie de la letra e invitaba a su mujer a hacer lo mismo. Su amigo personal es su confesor, adopta la opinión de la iglesia en cuestiones morales como su rechazo a la homosexualidad y le aborrecía hacer el amor con su mujer cuando da cuenta que el acto erótico perdió su finalidad religiosa como medio de procreación. Al final, el autor subraya su buena imagen a través de una opinión general al decir: "Ramiro es bueno; es guapo y es simpático. Todo el mundo está al tanto" (pp. 10, 16, 24, 27-29 y 30).

El tercer personaje es Pablo Costa, amigo de infancia de Desideria y su ángel de guardia más tarde. Reúne cualidades físicas y personales muy positivas. Es un modelo turístico. Representa la legalidad a través de su trabajo como agente en la Interpol (p 19). El último personaje es francés, Denis, prototipo para el sacrificio y el amante romántico. Ofrece a su amada, Desideria, todo tipo de sacrificios.

Viendo estos personajes occidentales desde la dicotomía, tema del presente trabajo, se podría comentar que Gala maneja en su creación la técnica de la antítesis. El recurre a esta técnica para realizar una comparación entre su personaje principal, Yamam, por una parte, y casi todos los demás, sobre todo Ramiro, Desideria, Pablo Acosta y Denis, por otra, para acentuar sus rasgos desfavorables. De este modo, el personaje oriental se convierte en un paradigma, o un conjunto de síntesis antitética negativa de estos personajes occidentales. En este caso, "estos personajes secundarios -según Julián Rodríguez- además de aliarse a una u otra figura principal, sirven de contraste a ella" (2017: 542). Una pincelada concreta que subraya esta técnica de contraste son las opiniones del marido de Desideria y Yamam respecto a la 
homosexualidad. Para Ramiro ésta le inspira "repugnancia" (p 30), por su parte, el personaje turco presume de que "el turco, a menudo, siente el atractivo de otro macho y se lía con él’'(p 60).

A través de esta antítesis, en muchos casos es fácil establecer esta relación antitética entre una cualidad positiva de un personaje español concreto y su contraria en este personaje. Mientras que Yamam se presenta como modelo de libertinaje, de falta de fe, de ilegalidad, de explotación y de oportunismo, sus antagonistas españoles son ejemplos de religiosidad, humanidad, legalidad y de sacrificio. Detallándolo un poco. Frente al profundo sentido humano de Desideria, Yamam se muestra cruel con su madre, y con la misma Desideria (pp. 83,97-98 y 105). En contraposición de Ramiro, modelo de religiosidad, Yamam representa, como un "persona vulgar", todo tipo de contradicciones. Él declara que no es musulmán y toma bebidas alcohólicas (pp. 72, 92 y 100). Al contrario de la legalidad de Pablo Acosta, Yamam, casi siempre, subraya su comportamiento fuera de la ley. (pp. 75 y 90). Por último, mientras que Denis se comporta con Desi de forma romántica, ofreciéndola todo tipo de sacrificios, Yamam es chulo, utilizaba su amada para todo como enganchar a sus clientes. Según Pablo Acosta, siempre la ha utilizado: "como criada, como cómplice, como dependienta, como mujer anuncio, como auxiliar de su narcotráfico" (p 126).

\subsection{La dicotomía en realidades sociales}

En relación con la dualidad a nivel de realidades sociales, Antonio Gala utiliza varias técnicas. La primera, partir de lo particular a lo general, el paralelismo, y el contraste. De momento tratamos las técnicas de uso limitado como el paralelismo. En cuanto al paralelismo, se muestra en las etapas de vida de Desideria. Cuando estaba ya residente en Estambul, desesperada por el abandono de su amante y ante el miedo de perderlo totalmente, se acuerda de otra etapa de su vida, la de su infancia en España. El autor hace una comparación entre su niñez grata y feliz en Huesca, con Pablo Acosta, y las vicisitudes de su vida con Yamam en Estambul (p 105). Otro ejemplo, el novelista establece una comparación entre los ambientes de una ciudad provinciana turca y Huesca; y entre Madrid y Estambul, donde sale ganando lo español, pues Madrid es "ser menos ruidosa y más civilizada" (pp. 58 y 94). El último ejemplo es la comparación entre personas. Ésta se realiza a menudo pero su centro de enfoque es Yamam (pp. 58, 69 y 111) (véase 2.1.2.).

La segunda perspectiva es el contraste, el cual se puede observar en la exposición del autor de cuatro viajes turísticos que Desideria había realizado con su 
marido hasta su residencia en Estambul con Yamam. Los viajes se realizaron hacia Colombia, Egipto, Siria y Turquía. Los países elegidos, siendo exóticos, cumplen con la característica del espacio en la novela romántica del siglo XIX. El punto de vista del novelista se ofrece a través de muchos elementos; a saber: el espacio dedicado a cada viaje, su desarrollo, su valoración, etc. El espacio dedicado se amplía de forma progresiva en el siguiente orden: Colombia, Siria, Egipto y Turquía.

\subsubsection{Colombia}

En este país, Colombia, perteneciente al primer mundo, el occidental, se observa que no existe ninguna descripción de detalles de vuelo ni a la llegada al aeropuerto, ya en seguida Ramiro y Desideria se encuentran en Cartagena. De forma general, se observa que el autor se limita a dar juicios positivos; sea a nivel de las relaciones entre Desi y Ramiro o a descripciones de paisaje. Desi dice: "Pasamos calor, pero fue un día hermoso. Vimos pájaros exóticos". Su valoración final es que ella y su marido estaban "animados y unidos más que nunca". El único inconveniente es el rechazo de Desi a los maltratos, a los cuales un hombre somete un animal llamado el perezoso (p 13).

No ocurre lo mismo con sus otros viajes a Egipto, Siria y Turquía; que pertenecen al segundo mundo: el oriental, Gala ofrece una descripción detallada a muchos aspectos de la vida, lo que le permite emitir comentarios, en su mayoría desfavorables.

\subsubsection{Egipto}

En el viaje de Egipto, págs. 27- 30, el escritor describe, minuciosamente, la excursión, lo que le da la oportunidad de opinar sobre distintos aspectos de Egipto: gente, comida, comportamiento, Administración, etc. Su opinión al final ha sido de connotación negativa ya que el viaje resultó "bastante deficiente" y ellos, por su buena voluntad, lo "recuerdan con gusto". Desi y sus compañeros no le gustaron nada en Egipto; la topografía, etc., incluso los monumentos. El sarcófago de Ramsés II, que normalmente sobrecoge a los turistas, da impresión de "humildad", y las pirámides parecieron a Ramiro "más pequeñas".

El interés del autor en destacar un aspecto concreto despectivo se observa en comentar muchos detalles que faltaron en el caso de Colombia. El aeropuerto, por ejemplo, donde aguardaban su avión es "minúsculo y desaseado". El desayuno que se les han ofrecido es "miserable". El vuelo de El Cairo al Alto Egipto es incómodo"sin domesticar". Allí, los servicios son "ínfimos" y "la mugre es 
insoportable". Los turistas "cuidaban sus comidas; espantaban sin cesar las moscas; se precavían contra las infecciones, y vivían en una continua sospecha". La ciudad de El Cairo es "un caos", y el turista se pierde en la zona turística de Jan el-Halili debido a sus "abundantísimas y enloquecedoras afluencias y diversificaciones". No ha escapado de los juicios del autor ni la misa que hizo Ramiro que es "una extraña ceremonia con muchos cantos y muchísimo incienso" (pp. 27-30).

\subsection{Siria}

En su descripción del viaje a Siria, páginas 31 y 32, el novelista sigue el modelo egipcio y evoca el personaje de Otelo, protagonista de la gran obra dramática de Shakespeare. Resume el contenido de esta obra así: "habla de un turco de allí mientras se degüella" ( $\mathrm{p} 31$ ). Como se aprecia, las notas selectas contienen una carga considerable de violencia, que se comentará más tarde (véase: 3.). Así, Gala establece una relación entre el pasado, el turco Otelo y el presente, el turco Yamam. La intención del autor se aprecia, igualmente, en hacer contraste entre un pasado glorioso de Alepo y un presente miserable. Según él:

En el primitivo cementerio de Alepo, hay un campo de fútbol; dentro de su gloriosa ciudadela se hace teatro; frente al lienzo de la muralla de Damasco por donde se descolgó san Pablo, hay un parque de atracciones.

Igualmente, esta opinión se deduce de las notas de índole despectiva. Por ejemplo, él se refiere a la colina de Alepo, diciendo que "estaba formada por los escombros de las civilizaciones, mientras que Damasco es la constante superviviente." En definitiva, Desi y su marido coincidieron en reducir el viaje a ser como hacer "unos ejercicios espirituales" (p 32).

\subsubsection{Turquía}

En el cuarto viaje, el de Turquía, el autor sigue el modelo de Egipto y Siria. Dada la amplitud de su exposición se le designará este apartado entero. Gala, aprovechando la estancia de su protagonista en la capital turca, amplía el espectro de sus juicios, tratando todos los aspectos de la vida, incluso la conducta de algunos animales, como el burro. 


\section{Dr Abdelaal Saleh Taha}

\subsubsection{Administración}

La Administración turca es corrupta -según Gala- "hasta las cejas", no funciona con leyes o reglamentos sino a base de amistades, enchufes y sobornos. Yamam cuenta cómo funciona: "en Turquía todos tenemos un primo que ocupa el puesto oportuno en cada circunstancia" (p 52). Pablo Acosta, por consejo de sus superiores, lleva regalos como botellas de bebidas alcohólicas, porque según él es "un modo de abrir caminos" (p 121).Este personaje, debido a la naturaleza de su trabajo es el encargado a dar información sobre la actividad de la mafia turca. En estos implica a muchos organismos de la Administración. Por ejemplo, los laboratorios legales que fabrican medicinas con el opio nacional, "fabrican mucho más de lo que les corresponde". La policía, por su parte, sabe lo que hacen y decomisa alguna parte de su producción de vez en cuando para disimular, porque "ella misma está implicada hasta las cejas". Sabe también que hay laboratorios muy cerca de las fronteras del Este que transforman la morfina en heroína, la "brown sugar" turca. En resumen;"Muchos de los miembros de la policía están muy bien comprados. La elite de esta policía no es mala, pero el conjunto es flojo" (p 126).

\subsubsection{Servicios}

En el caso de Turquía, el novelista sigue en la línea de Egipto y Siria. La primera nota, en este sentido, se ofrece en los detalles de la llegada del vuelo de Desi desde su país de origen al de su destino: Turquía. Su exposición de los viajes anteriores carece de este punto salvo unas pinceladas ligeras. En el primer viaje a Turquía, el autor muestra la modestia de los servicios del aeropuerto de Estambul, que se nota en los trámites de entrada, en la fealdad de las instalaciones, en la escasez de carritos para los equipajes y la tardanza de su salida a la cinta continua. Fuera ya del aeropuerto, el autobús que debería llevarlos a la ciudad no estaba. Luego muestra la reacción de Desi que creció en ella "un resentimiento previo", mientras que entre el grupo que la acompaña se había "propagado un aire de aprensión y de desconfianza" (p 40).

Notas iguales están esparcidas por toda la novela. Pero lo que podría reflejar mejor la tendencia del autor es su exposición a tres hechos similares donde el contraste es muy notable. Se tratan del parto de Desi en su país natal y los dos abortos en su nueva residencia. Dicha contraposición aparece en casi todos los elementos como: el tratamiento de la gente de su contorno, circunstancias profesionales; como el lugar de la clínica, equipos profesionales, preparativos sanitarios y la reacción de la paciente. Se intentará reflejar la perspectiva del autor a través del cuadro siguiente: 


\begin{tabular}{|c|c|c|c|}
\hline Aspecto & Parto & Primer aborto & Segundo aborto \\
\hline Lugar & $\begin{array}{l}\text { Huesca, en una } \\
\text { clínica oficial bien } \\
\text { equiparada. }\end{array}$ & $\begin{array}{l}\text { Estambul, casa de una } \\
\text { comadrona, en un } \\
\text { barrio muy popular. }\end{array}$ & $\begin{array}{l}\text { Estambul, una clínica } \\
\text { clandestina en un } \\
\text { barrio muy popular }\end{array}$ \\
\hline Naturaleza & $\begin{array}{l}\text { Acto social de bien } \\
\text { augurio. }\end{array}$ & $\begin{array}{l}\text { Acto ilegal, se hace al } \\
\text { margen de la ley. }\end{array}$ & $\begin{array}{l}\text { Acto ilegal, se hace a } \\
\text { margen de la ley. }\end{array}$ \\
\hline Contorno & $\begin{array}{l}\mathrm{Su} \text { marido y sus } \\
\text { amigas. }\end{array}$ & $\begin{array}{l}\text { La odiada madre de } \\
\text { Yamam y él. }\end{array}$ & $\begin{array}{l}\text { La odiada madre de } \\
\text { Yamam y él. }\end{array}$ \\
\hline Los profesionales & $\begin{array}{l}\text { Un profesional cont } \\
\text { su equipo. }\end{array}$ & $\begin{array}{l}\text { Una mujer que } \\
\text { masticaba algo verde. }\end{array}$ & $\begin{array}{l}\text { Un médico judío bajit } \\
\text { y una mujer tapada. }\end{array}$ \\
\hline Tratamiento & $\begin{array}{l}\text { Según el protocolo, } \\
\text { impuesto por la } \\
\text { medicina moderna }\end{array}$ & $\begin{array}{l}\text { Le dieron a oler éter o } \\
\text { una cosa parecida. }\end{array}$ & Sin anestesia. \\
\hline Ambiente & Ameno. & Hostil y con gritos. & $\begin{array}{l}\text { Hostil y con } \\
\text { gritos }\end{array}$ \\
\hline Reacción & $\begin{array}{l}\text { Colaborar con buena } \\
\text { gana. }\end{array}$ & $\begin{array}{l}\text { Le daba } \\
\text { asco. }\end{array}$ & $\begin{array}{l}\text { Preocupada por la } \\
\text { falta de anestesia. }\end{array}$ \\
\hline El resultado & $\begin{array}{l}\text { El nacimiento de } \\
\text { niño guapo. }\end{array}$ & Una hemorragia & $\begin{array}{l}\text { Le } \\
\text { esterilizaron. }\end{array}$ \\
\hline Sus sentimientos & $\begin{array}{l}\text { Es la más feliz del } \\
\text { mundo. }\end{array}$ & $\begin{array}{l}\text { Infeliz y no quiere } \\
\text { saber nada. }\end{array}$ & $\begin{array}{l}\text { Infeli } \\
\mathrm{z} .\end{array}$ \\
\hline
\end{tabular}

Reproducimos algunos pasajes que consideramos oportunos en cada caso. En su parto,

[Desi] no sentía el menor pudor porque el médico o sus ayudantes manipularan (su) cuerpo o ni lo abrieran. Su reacción final es que ella no recordaba haber sido nunca más feliz (pp. 66 -67). 


\section{Dr Abdelaal Saleh Taha}

En el primer aborto en Estambul "se olía el áspero y azufrado olor del lignito cuando se quema". Un ambiente ruidoso donde "unos hombres troceaban una gran masa oscura del lignito de las calefacciones". Desi, "le daba asco y apretó los párpados y no quiso saber ya nada más” (p 83).

Se podría advertir a través de este cuadro que el autor en estas tres escenas presenta dos mundos distintos o casi contrarios. El occidental donde hay medicina moderna en todos los sentidos: lugar sanitario, médico, ayudantes profesionales, medicamentos, ambiento ameno, legalidad y final feliz. Todo refleja modernidad, humanidad y respeto a los derechos del hombre en general y el enfermo en particular. El otro, el Oriental, donde todavía se ejerce los medios tradicionales y retrasados de terapia que ponen en peligro las vidas de los enfermos, ilegalidad, final trágico; no se respeta el ambiente, elemento importante en este contexto, ni la voluntad del paciente.

Como se señaló antes, nada de Turquía escapó de la observación y comentarios de nuestro escritor. Exponemos ahora su descripción sobre la topografía turca; es decir, Turquía como tierra, ciudades, geografía, etc. Turquía recibe del autor adjetivos como "desamparada, fatalista," y en ella se percibe "suciedad y miseria". Su hermosura es para él que "pueda pasar de largo y abandonarla, no para el obligado a padecerla" (p 57). Una región turca, Salónica, es un "lío de mares e islas" (p 40). Estambul, su ciudad más importante, se describe como desprovista de embrujo, incomprensible, velado por la contaminación y por el polvo; y comparado con Madrid, resulta la capital española demasiado tranquila y muy civilizada. Su agua, sea de grifo o embotellada, es peligrosa, que "no le ocurre a nadie tomarla", según unos análisis hechos en Suiza. En la pista de su aeropuerto yace una nieve sucia y amontonada (pp. 69 y 88).

Dejando Estambul, las zonas rurales sufren de un abandono y una escasez de servicios como las carreteras modernas. Ciertos pueblos son de tan imposible acceso que es necesaria "alquilar caballerías para llegar a ellos" (p 57). El restaurante principal de un pueblo grande está plagado de moscas. Como remate a esta descripción, el novelista nos informa que los burros turcos son de demasiado carácter y chovinistas (p 57).

\subsection{La dicotomía en el nivel léxico-semántico}

En la parte anterior de este trabajo hemos expuesto la dicotomía en personajes, y realidades sociales. En el presente apartado vamos a subrayar esta imagen a través de los vocablos y términos. En primera instancia, podemos confirmar que las palabras en negrilla en los distintos apartados demuestran la dicotomía a nivel léxico-semántico. 


\section{- El léxico-semántico en la caracterización de los personajes}

En la caracterización de los personajes orientales, Gala usa un vocabulario en su totalidad de índole negativa. Igualmente, se puede apreciar que muchos adjetivos formarán una caracterización de fuertes rasgos de indiscutible connotación negativa como: "gorda, gruesa, un turco se degüella, sinuoso, famoso por su habilidad para engañar, vociferantes y bebidos, un turco seco, granujiento, de malísima catadura, hombre oscuro, con una cicatriz de la sien a la boca, selva, jauría",..etc. Por otra parte, en el caso que dichos personajes sean mujeres el novelista utiliza una cualidad indeseada respecto a su género como "gruesa, sonrisa siniestra, gorda, comer con fruición, bruja, sombrilla", etc.

Otro recurso semántico es la contraposición que se puede hacer entre las palabras que se usan en la descripción de Yamam, de una parte y las otras que se utilizan en calificar a los otros personajes, de otra. Fíjese en lo siguiente: Ramiro es "guapo, simpático". Desideria es "una santa. Un ejemplo a mis penitentes". Pablo Acosta es un "anuncio de turismo". Mientras que Yamam es "holgazán, capaz de vender a su madre, tiene una fama atroz: de mujeriego, un turco vulgar". Obsérvese los matices positivos de los vocablos correspondientes al primer grupo; como guapo, santa, etc., y casi sus antónimos; como mujeriego, holgazán.

\section{- El léxico-semántico en la descripción de las realidades sociales}

En el caso de los viajes a países orientales, se observa que nuestro escritor ha manejado un vocabulario de carácter despectivo. Sustantivos como: "mugre, moscas, infecciones, humildad, caos, escombros, superviviente". Verbos en una forma verbal, pretérito imperfecto, que indica continuidad: "espantaban; precavían". Adjetivos: "deficiente, minúsculo, desaseado, miserable, insoportable, enloquecedor, extraña". Locución: "continúa sospecha". Desde el punto de vista semántico, todos estos elementos expresivos tienen relación con la falta de higiene, de orden, de modernidad, un nivel ínfimo de servicios, y dan la impresión de un mundo primitivo, retrasado, ajeno a la amenidad, el bienestar y el goce. Nótese, igualmente, en los siguientes vocablos:"aprensión, desconfianza, lignito, trapo, hemorragia, asco, esterilizar, fatalista, suciedad, miseria, contaminación, polvo, gruesa, sonrisa siniestra, gorda, bruja, sombrilla, plagado de moscas, lío", etc. Estos están en consonancia con la tendencia patente del autor de hacer una exposición de connotaciones negativas al mundo oriental. 


\section{Dr Abdelaal Saleh Taha}

\section{Hacia una interpretación.}

\subsection{Introducción}

A lo largo de la parte anterior, hemos podido demostrar la dicotomía de mundos narrativos por medio de la exposición de dos mundos con distintas formas de novelar: el pre-turco y el turco, o mejor dicho, el occidental y el oriental que incluye Egipto, Siria y Turquía. Esto constituye el primer objetivo conseguido en este trabajo. En ambos mundos, el autor realiza un proceso selectivo de todos los componentes: personajes, espacio, sucesos, etc. En el mundo occidental su selección se concentra, como se dice, a la flor y la nata, mientras que en el segundo se tiende hacia lo popular y marginal. Para confirmar nuestra observación llamamos la atención sobre los viajes que hizo Desideria durante su residencia en Estambul. Entre estos se destacan dos viajes relámpagos, en el primero visitó a Madrid, su espacio es nada menos que el Paseo de la Castellana, la zona más céntrica y moderna de la capital española. En el segundo viaje se fue a París, el espacio elegido es las orillas del rio Sena y la zona comercial más lujosa. Pero cuando Desideria viaja dentro de Turquía visita la "Turquía profunda" y rural, zonas a los cuales no llegó el progreso, ni la modernidad. En términos generales, en el mundo occidental la exposición se concentra en lo positivo, con ligeros rasgos negativos, en su mayoría de carácter sentimental. Por otra parte, en el oriental, se centra en lo negativo, con ligeras pinceladas positivas. Se tratan de una descripción de algún paisaje o algún monumento (pp. 107,118). Lo anterior es producto directo de la selección antedicha de elementos y su correspondiente falta de similitud entre los elementos puestos en contraposición y tienen el orden siguiente:

\begin{tabular}{|l|l||}
\hline \multicolumn{1}{|c||}{ Mundo occidental } & \multicolumn{1}{|c|}{ Mundo oriental } \\
\hline \hline Personajes: de elite social & Personajes: criminales \\
Zonas: urbanas y céntricas & $\begin{array}{l}\text { Zonas: populares, rurales y } \\
\text { campesinas } \\
\text { europeas }\end{array}$ \\
Espacio: familiar y social & $\begin{array}{l}\text { Espacio: comercial y } \\
\text { criminal. }\end{array}$ \\
\hline
\end{tabular}

Billat coincide con nuestra evaluación y comenta esta forma de ver la realidad del segundo mundo narrativo, el oriental, diciendo que: 
En La pasión turca se presenta al extranjero de un modo estereotipo.

Tal representación subraya cómo ciertos europeos construyen al mundo árabe, africano o asiático según su visión europea (2004: 5).

No cabe duda de que situaciones, comportamientos, personajes, espacios, instituciones como los expuestos por el novelista existen, sea en Egipto, Siria o Turquía. En este caso, aunque esta forma de novelar sea realista, pero la perspectiva, que toma la forma de un proceso de selección por parte del autor, -según Gil Casado"falsea la realidad" (1975: 63-64). Además, desde nuestro punto de vista, condujo a crear una obra cuyos recursos narrativos han sido subordinados a un fin no artístico, sea lucrativo o ideológico, lo cual constituye un defecto de gran calibre para la obra.

Ahora es el momento de contestar algunas preguntas que constituyen el segundo objetivo de nuestro trabajo: ¿Por qué Gala hizo sus mundos así? ¿Qué tipo de factores desempeñó un papel decisivo en esto? Podríamos interpretar la índole de este fenómeno según las respuestas obtenidas.

\subsection{Interpretación}

Después de la exposición anterior queda demostrado que Antonio Gala describe el Oriente; gente, realidad, situación urbana, sobre todo a Turquía; un país conocido hoy día por su progreso a nivel social, político y económico, con rasgos desfavorables.

El hecho de explicar esta actitud del autor se ve complicado por muchas razones. Entre éstas se destacan sus opiniones favorables conocidas en otras obras respecto al mundo árabe-islámico ${ }^{2}$. También, su mutismo sobre el mensaje de su obra y sus declaraciones que no aportan casi nada. Igualmente, no se puede pasar desapercibido el contenido de algunas partes de su exposición en esta novela que indica que él sabe bien la imagen estereotipada del Oriente, incluso que está en su favor. Como muestras de la actitud del novelista favorable a dicha imagen estereotipada son los comentarios que hace después de reflejar la postura negativa de los españoles hacia Turquía. Esta actitud se ve claramente en muchos pasajes de la obra. Por ejemplo, Desi tenía "resentimiento previo de que aquel país no le iba a gustar nada" ( $p$ 40). En la misma línea, nuestro escritor parte de lo general a lo particular, y expone la idea que tienen los europeos en este punto: "el turco era un concepto ominoso, amenazador y cuajado de inopinados albures", por eso "(Desideria) sentía contra los turcos esa enemiga subconsciente e histórica de los europeos" ( p 39). Estos sentimientos e ideas han constituido en ella una reacción anti 
turca (p 71). En cuanto a su apoyo, Desi, alter ego del autor, comenta que los extranjeros en Estambul no tienen confianza en los turcos y siempre piensan que cualquiera turco desea sacar tajada de ellos. Ella comenta que "tienen razón y no puede reprochárselo". Igualmente, cuando expone los prejuicios de su protagonista, Desideria, lo glosa diciendo: "el tiempo, sin demorarse, iba a demostrar que estaba cargada de motivos en cuanto a su actitud de Turquía y su gente" (p 39). Respecto a su justificación, el autor menciona las diferencias culturales entre Occidente y Oriente. Partiendo de estas diferencias, la protagonista siente que Turquía es "menos suya" ( $p$ 106), y Yamam, símbolo del Oriente, no tendría la misma manera de entender la mayor parte de las cosas ( $\mathrm{p}$ 52).

Parece que para resolver este dilema, sus opiniones anteriores favorables al mundo árabe-islámico, y su exposición negativa en esta novela, hace falta suponer unas explicaciones. La primera se puede deducir del estudio de Emilia Cortes Ibáñez. Según este estudio, el autor, en su intento de manifestar los sentimientos de Desi en su aventura, utiliza una técnica que enfatiza un tiempo "psicológico interiorizado", que se proyecta sobre las vivencias interiores de la protagonista (2017: 36). Dado que la mayor parte de este tiempo tiene lugar en Turquía, precisamente en Estambul, las descripciones de Desi a dicho país se ven afectadas por su estado de ánimo desesperado ante su fracaso de dominar a su amante. Partiendo de esta observación, las notas negativas contenidas en la obra serían reflejo de su estado sentimental amargado y desesperado.

La segunda explicación es la de la profesora A. Billat, quien tiene dos interpretaciones. La primera relaciona esta obra con un fenómeno social inverso: la inmigración extranjera en España, que en el período de la publicación de la obra adquirió una singular importancia. Según ella, Gala tiene como punto de partida la mezcla de fascinación y de ansiedad que la España postfranquista siente hacia el extranjero (2004:42). La segunda interpretación explica la obra como un proceso de realización de la protagonista como mujer en tres dimensiones: como esposa, madre y querida. Desi fracasa en estas tres vertientes. Billat termina diciendo que parece que el novelista "critica, mediante su novela, la construcción estrecha del género sexual" (2004: 5-43).

Desde nuestro punto de vista, la última explicación deja muchos interrogantes relativos al contenido de la novela sin contestar, como los siguientes: ¿Qué simboliza la muerte de Carlos, un homónimo del emperador Carlos V conocido por su lucha contra los turcos, y los dos abortos posteriores? ¿Por qué los dos abortos se realizaron por una voluntad oriental? ¿Por qué el escritor insiste en erradicar cualquier tipo de continuidad material de las relaciones entre Yamam y Desideria? ¿Por qué el autor optó por un personaje oriental, Yamam, y no lo hizo por un latino, un cubano por 
ejemplo, etc., cuyo país es exótico igual que Turquía, y con ello el autor hubiera podido exponer su tema mencionado antes; evitando el obstáculo de las diferencias culturales?

La tercera interpretación es de carácter social e ideológico. Decimos, si aceptaríamos la opinión del mismo autor y sus pocos críticos se podría suponer un interés social por su parte. El dice: "tengo la idea de que la literatura cumple una misión, una función social" (José infante ,1994: 38-39). La periodista Carmen Díaz Castañón señala que en la obra literaria de Gala hay una intención de participar con su escritura en las luchas de su tiempo (José infante, 1994: 27). Según José Infante los críticos de izquierdas lo proclamaron como un gran autor comprometido debido a la carga social en su obra Los verdes campos del Edén (1994: 115). Esta intención aparece también en sus dos obras: La vieja señorita del paraíso y El cementerio de los pájaros. La primera es una crítica a la OTAN, mientras que la segunda tiene como fondo el golpe de Estado que se produjo en España en el 23 de febrero de 1981 (Gala: Noviembre...1988: 26 y 29).

En este sentido, cabe proponer que Gala expone en forma narrativa un modelo de las relaciones eróticas entre españolas y extranjeros, sobre todo orientales. Asensio Moreno en su comentario menciona esta posibilidad. Señala que este tipo de relaciones es algo que ocurre muy frecuentemente (1996: 127). Aunque se puede aceptar que esto podría constituir un fenómeno, pero no de tan calibre ya que las estadísticas al respecto indican que el número de matrimonios españolas-orientales en 2008 no sobrepasó los tres mil ${ }^{3}$.

Por nuestra parte, pensamos que, dado el conocimiento de nuestro novelista de la imagen estereotipada y su postura casi favorable al mismo, su aportación social en esta novela podría ser ofrecer un tema de alcance ideológico: su opinión respecto a "la posibilidad de un encuentro entre el Oriente y el Occidente". La cual se lleva a cabo a través de esta presentación narrativa de las relaciones eróticas entre españolas y extranjeros. Como indicios que apoyan nuestra hipótesis se encuentran los puntos siguientes: su evocación de un tópico popular asombroso: los sobacos del turco; que, precisamente, es una parte de un refrán con matices despectivas, su mención de palabras como harén y Sultán, y su presentación de una escena erótica tripartita. Todos estos tienen relación con tópicos sobre la vida oriental, resucitando así su leyenda negra (pp. 56, 71, 78 y 131).

Teniendo en cuenta nuestros antedichos interrogantes que cuestionan la interpretación de la profesora Astrid, se podría suponer que la opinión de Gala 


\section{Dr Abdelaal Saleh Taha}

subraya la dificultad de un encuentro entre ambos mundos, simbolizada en la falta de continuidad material en el tiempo de las relaciones eróticas de Desi y Yamam, el niño Carlos muere, etc., y ella se suicida. En este sentido, destaca su referencia a la gran obra de Shakespeare, Otelo, y su uso de la primera parte del nombre de la protagonista del dramaturgo inglés "DES", Des/démona - Des/ideria, como una abreviatura del nombre completo de su personaje femenino con matices sentimentales "DESI". Como se sabe, Otelo termina de forma trágica. El protagonista oriental asesina a su esposa occidental, por razones morales y se suicida. Ambas obras, partiendo de sus fines, supondrían que el encuentro entre las dos partes del mundo: Oriente y Occidente no es tan fácil debido a las diferencias culturales. ${ }^{4}$

Partiendo de la opinión de Billat antedicha y Asensio Moreno sobre el uso del novelista de tópicos y convencionalismos, se podría señalar que Antonio Gala ha caído dentro de los marcos negativos de la Teoría de Otredad. Aunque ésta podría tener una concepción positiva como un medio a "la diversidad que -según Said- es necesario reconocer para articular espacios públicos democráticos"(Zapata Silva, 2008:72), a nivel práctico esta noción constructiva ha sido omitida, ofreciendo otra. Según ésta el otro, en este caso el Oriente, sobre todo sus ciudadanos, configura depende de una red compleja de intereses de todo tipo; políticos, económicos, históricos, incluso personales, donde se lo ve como algo distinto, y en muchos casos se considera un mundo de bárbaros, sin educación y cultura, y salvajes. La cuestión se agrava cuando existen unas relaciones históricas, de forma general, conflictivas entre las partes implicadas como; al oriente musulmán, sobre todo los turcos, y los españoles. No hace falta hacer hincapié sobre la rivalidad política entre los turcos y los europeos, especialmente los españoles, durante los siglos XVI y XVII sobre la hegemonía militar del mediterráneo, cuya expresión más clara se da en la famosa batalla Lepanto, en la cual quedó Cervantes manco, y desde entonces comenzó una literatura de temática anti-turca, con participación activa, precisamente, por parte del autor del Quijote, sobre todo, en su comedia La gran sultana. Goytisolo analizó, de forma magistral, esta campaña en su libro Crónicas Sarracinas. Debido a esta situación es normal que el Oriente se ve desde los estereotipos heredados.

La última interpretación es relativa a conseguir el éxito editorial. Gala ha incluido en su obra rasgos de más de un género novelístico, conocidos por ser gran aceptación por parte de los lectores, que condicionaron su forma definitiva, sobre todo en su creación del segundo mundo. En este punto han coincidido Carmen Rigalt, y Asensio Moreno. Según la primera, la obra contiene "los ingredientes necesarios para gustar. Turquía, el adulterio, la pasión, el desamor, el engaño y finalmente, la inmolación" ( $\mathrm{p}$ 2). Es decir, una confección hecha a medida de la demanda de los lectores. Por su parte, Asensio Moreno señala que el novelista para tener éxito ha 
caído en todos los tópicos, todos los convencionalismos, manejando hasta la saturación las frases hechas y los valores entendidos (1996: 127). Obsérvese que "los tópicos", y "los convencionalismos", en los cuales ha caído nuestro novelista son, precisamente, los aspectos de su segundo mundo narrativo. Recuérdese: harén, sultán, etc. El propio Gala ha dicho que las mujeres (que constituyen la mayor parte de sus lectores) son las que marcan los éxitos en España (1996: 127). En este sentido, el género policiaco ocupa el primer puesto. Amorós lo considera como un factor importante de éxito, lo cual se muestra en su gran difusión que debe a su "enorme desarrollo y [ser] un hecho cultural de evidente importancia" (1981:125). Gala declaró, de forma categórica, que su obra es policíaca. "tu historia, (dirigiéndose a Desideria) - según Gala- se reduce a una historia de narcotráfico" (p 126). Los rasgos de este género se dan en la misma intriga de La pasión. Estos son: la investigación de unas sospechas de índole criminal, el ambiente de suspense, misterio y sospecha, y la naturaleza de sus personajes y su implicación con el mundo del crimen. Salvo anécdotas de corte romántico y discurso enciclopédico que pertenece a los libros de viajes, el clímax es más propio del género policíaco.

El segundo género corresponde a los libros de viajes. La importancia de este género para conseguir el éxito editorial es indiscutible. Los novelistas recurren al elemento de los viajes para garantizar el éxito de sus obras y complacer los deseos de lectores y editores. Amorós apunta que "tantas novelas mediocres se benefician de la permanente fascinación que ejerce sobre el espíritu humano el tema del viaje" (1981:11).La pasión contiene los dos rasgos principales de este género: la existencia de un discurso narrativo y otro enciclopédico. Además, esta obra tiende, de forma general, a resaltar la superioridad del país de origen del autor, España, respecto al referido en su obra, el Oriente, como lo hicieron algunos autores de dicho género. La última característica es propia de los personajes, que muchos de ellos, según Gil Casado, son anónimos y aunque se identifican con algún suceso no disponen del relieve necesario para que se destaquen del fondo del libro (1975: 449). Podríamos confirmar que los rasgos de los libros de viajes son una de las principales causas de esta presentación del mundo oriental. Asensio Moreno confirma esta resolución al decir que: "el segundo cuaderno, donde la descripción de Turquía, es tan acartonado que en seguido se nota que el autor nos está endilgando lo aprendido en dos o tres guías de turismo que ha consultado[...]Por lo visto hay que caer en todos tópicos, todos los convencionalismos" (1996: 127).

El tercero es el romántico. Se observa en el estado de desánimo de la protagonista y a su predilección por los elementos negativos. La obra contiene muchas notas que confirman su vinculación con este género narrativo. De estas se 
destacan las siguientes: como citar nombres de autores u obras románticos, Werther, Flaubert, la inserción de los famosos versos del poema Canción del pirata del poeta romántico José de Espronceda, la exposición de unas digresiones filosóficas sobre el amor, etc. y el fin trágico de muchos personajes como Desi y Mahmud (pp. 101, 104,115 y 137). Dicho patrón romántico da la oportunidad de enjuiciar al otro; sea país, pueblo, religión, etc., partiendo de unas posturas políticas e ideológicas. La misma España y los mismos españoles han sido víctimas de este aspecto cuando los primeros "románticos" de otros países, como en obras : el Don Carlos (1787) de Schiller o el Egmomt (1788) de Goethe, y la novela romántica madura, por ejemplo en promessisposi (1827/1840-42) de Manzoni, etc., fomentaron temas que los desprestigiaron (Ucelay Da Cal , 2017: 28). Eso explica lo que ha hecho Gala en esta obra, cayendo -según Asensio Moreno - "en todos los tópicos, todos los convencionalismos" (1996: 127). Esto, precisamente, lo que encontramos en La pasión turca, pero esta vez se refiere al mundo oriental.

Confirman esta interpretación algunos críticos como Gonzalo Navajas (2002: 19). Asensio Moreno (1996: 123) y Regueiro Salgado que consideraron que la carga erótica que tiene la obra se debe a este fin, editorial. Igualmente, coinciden en que el autor se preocupó por complacer el lector, aunque Regueiro Salgado piensa que un error reducir los objetivos de un escritor a esta finalidad lucrativa (2009: 315 y 613).

Recapitulando, la interpretación que tiene más peso es el logro de éxito editorial. En ella el autor hizo coincidir su exposición con los prejuicios existentes en el inconsciente de una parte de los españoles para formar una imagen atractiva desde el punto de vista de los principios de comercialización editoriales de las obras de entretenimiento y pasatiempo. Lo que apoya nuestra interpretación son los ingredientes mencionados por Carmen Rigalt. Son de especial importancia los elementos de sexo y policiaco. El diagrama anexo n0 1 resume lo antedicho.

\section{CONCLUSIONES}

Teniendo en cuenta la hipótesis propuesta, se ha llegado a las conclusiones siguientes:

- A nivel estructural, la obra refleja una dicotomía que se da en la descripción de dos mundos narrativos con diferentes formas de novelizar: el primero, el occidental, se compone de tres lugares Colombia, España y Francia, y el segundo, el oriental. En este mundo, el autor opta por exponer lo positivo, eligiendo personajes, espacio, etc. que componen una imagen de un mundo civilizado y moderno. El segundo mundo narrativo, el oriental, se ofrece a 
través de tres viajes a Egipto, Siria y Turquía. En este caso, el novelista actúa de forma contraria, concentrándose en los aspectos negativos, seleccionando elementos narrativos que dan la impresión de un mundo retrasado, corrupto y primitivo.

- A nivel técnico, esta dicotomía es el resultado del uso de la técnica de "omnisciencia multi-selectiva", que se basa en un proceso de selección de elementos narrativos, como personajes, etc. en ambos mundos. En este proceso, el escritor sigue en su caracterización de los personajes orientales, en la mayoría de los casos, una técnica que parte de lo particular a lo general. Después de atribuir unos rasgos al personaje oriental de Yamam, Antonio Gala los proyecta a todo su pueblo, y a todo el Oriente. Igualmente, sus descripciones negativas de Egipto y Siria preceden a sus observaciones peyorativas; retraso, ignorancia, etc., que confirmará después en la parte correspondiente a Turquía.

- A nivel léxico-semántico, la dicotomía toma la forma del uso de dos registros léxicos casi antónimos. De forma general, los vocablos correspondientes al mundo occidental son de matices positivos, mientras que los que corresponden al mundo oriental son negativos.

- En este trabajo, se ha ofrecido varias interpretaciones para explicar la forma con la cual presentó Gala el mundo oriental, y existen pruebas que acreditan, más o menos, a todas. Sin embargo, consideramos que la interpretación más idónea es la relativa a conseguir un éxito editorial, que originó la opción del autor por unos rasgos concretos de más de un género novelesco, lo cual condicionó la forma definitiva de la obra, sobre todo el segundo mundo narrativo, el oriental. De forma concreta, su obra reúne rasgos románticos, de los libros de viajes y policíacos.

- La pasión turca está hecha desde una perspectiva mercantil y de consumo; como una obra de entretenimiento. Tampoco, se puede descartar otra interpretación, la ideológica. Según ésta, Antonio Gala supone que el encuentro entre los dos mundos expuestos en la obra, occidental y oriental es

- difícil, debido a muchas diferencias, sobre todo las culturales. 


\section{Dr Abdelaal Saleh Taha}

\section{BIBLIOGRAFIA}

Amorós, Andrés, (1981), Introducción a la novela contemporánea, Cátedra, 7 edición, Madrid.

Asensio Moreno, Manuel (1996), vida y secretos de Antonio Gala, ediciones de Revista heterodoxia, Madrid.

A.Billat, Astrid (2004), La imposibilidad de la mujer en cinco novelas postfranquista, Currents in Comparative, Romance Languages and literatures, Peter Ling Publishing, inc. , New York.

Cortes Ibáñez, Emilia: El cronotopo de la pasión turca.

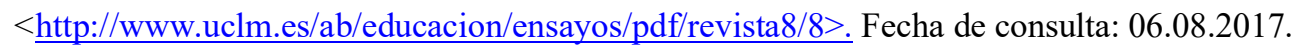
Gala, Antonio, (1981), Temas vivos, "Encuentro", números 105-106, enero-febrero.

(1985) Paisaje con figuras, selección Austral, n0 137. Edit. Espasa Calpe, Madrid. (1987), Al-Ándalus, tradición, creatividad y convivencia. Congreso internacional XII centenario de la mezquita de Córdoba, Córdoba.

(1988), Noviembre y un poco de yerba- Petra regalada, ediciones Phyllis Zaltinboring, cátedra, letras hispánicas, Madrid.

-------- (1990), Manuscrito carmesí, edición Planeta, Barcelona.

(2001): La pasión turca, prólogo de Carmen Rigalt, serie Biblioteca El mundo, Bibliotex Barcelona.

Garrido Domínguez, Antonio, (1993) el texto narrativo, editorial síntesis, Madrid.

Gil Casado, Pablo, (1975) La novela social española, 2a edición, Editorial Seix Barral, Barcelona.

Goytisolo, Juan (1982), Crónicas sarracenas, editorial Ruedo ibérico, Barcelona.

Jerez Farrán, Carlos (1992), "Las bodas de Doña Carnal y Don Cuaresma en Cinco horas con Mario" en Actas del X Congreso de la Asociación Internacional de Hispanistas, Barcelona 21-26 de agosto de 1989 / coord. por Antonio Vilanova, Vol. 3, ISBN 84-7665-116-3, págs. 3-18.

Infante, José (1994), Antonio Gala, un hombre aparte, editorial, Espasa-Calpe, Madrid.

Navajas, Gonzalo, (2002) Ficción y erotismo. La reubicación del cuerpo en la ficción española contemporánea, Verba hispánica, X, págs. 13-23.

Regueiro Salgado, Begoñia (2009), La poética del segundo romanticismo, tesis doctoral, Facultad de Filología, Universidad de Complutense de Madrid.

Rodríguez Salgado, M. J.: Felipe II "Paladín de la Cristiandad" y la paz con el turco, secretariado de publicaciones e intercambio editorial, universidad de Valladolid, pág. 176. $<$ http://www.jstor.org/page/info/about/policies/terms.jsp $>$ Fecha de consulta: 05.07.2017.

Rodríguez, Julián, GLOSARIO de Las Estaciones de la Imaginación. Disponible en línea. $<\mathrm{http} / / /$ las estaciones de la imaginacion.blogspot.com/>. Fecha de consulta: 08.05.2017

Ucelay Da Cal, Enrique: Ideas preconcebidas y estereotipos en las interpretaciones de la guerra civil española: el dorso de la solidaridad.

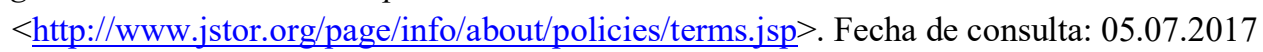
Viega Rodríguez, Francisco (2006), El turco, diez siglos a las puertas de Europa, debate, Barcelona, Random house, Monda. 
Villanueva, Darío, (1995), El comentario de textos narrativos: la novela, ediciones Júcar, Barcelona.

Vox: Diccionario manual ilustrado española, revisión y prólogo por Samuel Gili Gaya, $13^{\mathrm{a}}$ edición, Barcelona, 1985.

Zapata Silva, Claudia (2008). "Edward Said y la otredad cultural”. Ateneo 498.II Sem.

El diagrama anexo n0 1

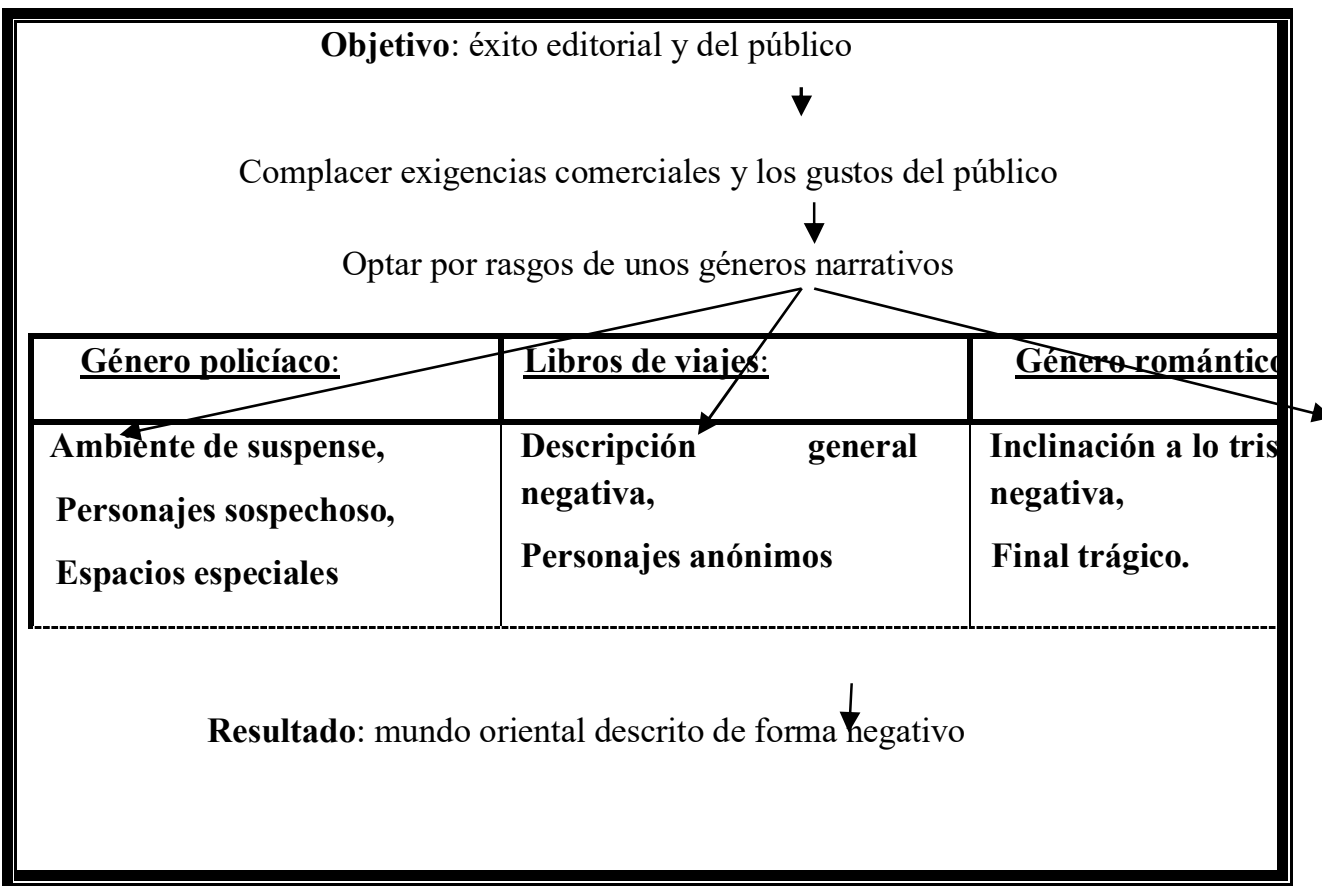

${ }^{1}$ La edición de la novela que utilizamos en este trabajo tiene los datos siguientes: Gala, La pasión turca, serie Biblioteca El mundo, Barcelona, Bibliotex, 2001. En el presente trabajo nos referimos a ella con la forma siguiente: ( $p$ ) y la negrilla es nuestra salvo que se notifique lo contrario.

${ }^{2}$ Antonio Gala: Temas vivos, "Encuentro", números 105-106, enero-febrero, 1981, pág. 3.

Ibíd. : Paisaje con figuras, selección Austeral, n0 137. Edit. Espasa Calpe, Madrid, 1985, págs. 39, 40, 41, 42, 118; tomo II, págs. 257, 264, 293-303.

Ibid.: Manuscrito carmesí, edición Planeta, Barcelona, 1990, págs. 25, 34, 42, 43, 67y 127.

Ibíd: Al-Ándalus, tradición, creatividad y convivencia. Actas Congreso internacional XII centenario de la mezquita de Córdoba, Córdoba, 1987, pág. 118. 
${ }^{3}$ Según las estadísticas de 2008, el número total de españolas casadas con orientales o africanos es 2743. La cifra más alta corresponde a Marruecos con un total de 1570, mientras el de Argelia es 163. Por cierto no figura en la lista el nombre de Turquía.

http://www.publiboda.com/estadisticas/matrimonios extranjero.html. Fecha de consulta 06.08.2017.

4 Es necesario hacer una apreciación respecto a la postura de los dos escritores, Shakespeare y Antonio Gala. El autor de Otelo estaba en consonancia con la situación histórica y política de su tiempo. Europa y el mundo islámico, representado en el imperio turco, estaban en pleno conflicto. Según Rodríguez Salgado el turco era "el enemigo de la cristiandad." Por su parte, Francisco Veiga Rodríguez lo califica de ser "el principal enemigo de Carlos V y Felipe II". Todo lo contrario en el caso de Antonio Gala. Desde la década en la que se publicó la obra, la última del siglo $\mathrm{XX}$, los intelectuales y políticos de ambas partes efectuaron muchos esfuerzos tendentes a hacer posible un encuentro entre ellas. En esta perspectiva viene la labor de Juan Goytisolo y su intento de desarticular dicha imagen estereotipada.

A nivel político, precisamente, el primer ministro español, José Luis Zapatero, y su homólogo turco lanzaron el año 2005 la iniciativa de crear un Foro Mundial de la Alianza de Civilizaciones, cuyo fin es combatir el terrorismo internacional por otro camino que no fuera el militar. Incluso España ha sido pionera en este campo creando en 2006 la Casa Árabe, el Instituto Internacional de Estudios Árabes y del Mundo Musulmán y la Asociación de Amistad Hispano-árabe, que el propio Gala ocupó su presidencia.

Véase: Rodríguez Salgado, Felipe II "Paladín de la Cristiandad" y la paz con el turco, secretariado de publicaciones e intercambio editorial, universidad de Valladolid, pág.

176. $<$ http://www.jstor.org/page/info/about/policies/terms.jsp $>$ Fecha de consulta: 05.07.2017. Viega Rodríguez, (2006: 13). 